\title{
A Comparative Study of Electrocautery Versus Cold Scalpel For Skin Incision In Inguinal Hernia Repair
}

\author{
Ansari $\mathrm{MA}^{1}$, Mishra $\mathrm{SM}^{2}$, Baskota $\mathrm{BD}^{3}$
}

\begin{abstract}
Introduction: Electrocautery has been widely used except for the skin incisions; this is because of the fear of scarring of skin, post operative pain, poor wound healing and wound infection in view of devitalisation of tissues. Although still not very popular, yet the use of diathermy instead of scalpel for making skin incision and underlying tissue dissection is gradually gaining wide acceptance. The purpose of this study was to compare the scalpel incision with electrocautery incision over skin in patients undergoing hernia repair. Aims and Objectives: To compare the skin wound made by the diathermy and scalpel with a view in; intraoperative incisional time, post operative pain, requirement of analgesia and the quality of wound healing. Material and Methods: This is hospital based comparative study, undergone elective inguinal hernia repair in the department of general surgery at Nepalgunj medical college teaching hospital, Kohalpur from the period of July 2015 to January 2016. Group A, contained 30 patients who underwent skin incision with scalpel and Group B, also contained 30 patients who underwent skin incision with electrocautery. These groups were compared and statistical analysis using SPSS (version 20) was done and p value 0.05 was taken as significant. Results: Compared with a scalpel incision, cutting diathermy resulted in significantly shorter incision time $(p<0.002)$. The two groups did not differ in relation to post operative pain and the post operative analgesics requirements. The postoperative complications viz, seroma and purulent collections were in both the groups though the hematoma collection was seen more in scalpel skin incision. Conclusion: Skin incision made by cutting diathermy was less time taking and there was no appreciable differences in postoperative pain, the requirements of analgesia and the rate of wound complications like seroma, and purulent collection, though the hematoma was seen more in scalpel skin incision. So the use of diathermy for making skin incision is as safe as the use of scalpel in patients undergoing inguinal hernia repair.
\end{abstract}

Key words: Electrocautery, scalpel, diathermy, postoperative pain

\section{INTRODUCTION}

Traditionally, surgical skin incisions have been made with steel blade. This method of making skin incision is an old method and surgeons have always been in search of some new methods for making surgical skin incisions because incision made by scalpel were supposed to be more bloody, time consuming and more painful $^{1,2}$. To overcome such problems laser and cavitron electronic surgical aspirator have been introduced, but these instruments are costly ${ }^{3}$. Electrocautery was developed by Dr. Bovie in 1909 to fulgurate tumors but was first used in clinical surgery by Dr. Harvey Cushing in 1926. It has now become an integral and evolving part of surgical practice. However, most surgeons still make skin incision with a scalpel and divide the deeper structures with coagulation diathermy ${ }^{4}$.

The use of scalpels for surgical incisions dates back to ancient

1. Dr. Meraj Alam Ansari

2. Prof. S. M. Mishra

3. Dr. B. D. Baskota

Address for correspondence:

Dr. Meraj Alam Ansari

Department of Surgery

Nepalgunj Medical College \& Teaching Hospital,

Kohalpur, Banke, Nepal

Email: meraj.ansari1100@gmail.com
Egyptian times. They used obsidian, which is naturally occurring volcanic glass, to make incisions for embalming. Modern surgical scalpels are usually made of hardened steel for better sharpness and precision. Basic scalpel design has remained almost the same but there has been a substantial improvement in the electrosurgical instruments ${ }^{5}$.

Fear of deep burns with diathermy and the resultant scarring continues compared with the scalpel, which produces a clean, incised wound with minimal tissue destruction. Cutting diathermy incision with an electrode delivering pure sinusoidal current allows tissue cleavage by rapid cell vaporization without damage to surrounding areas. This may explain the absence of tissue charring and subsequent healing with minimal scarring. Cutting diathermy can make hemostasis quicker and satisfactory, save the operative time, and can produce an incised wound that heals like the one created by cold scalpel ${ }^{6,7}$.

Many other studies have been conducted to compare electrocautery skin incision over scalpel skin incision in terms of time taken for incision, postoperative pain and wound healing especially in cases of inguinal hernia surgery, some have reported that the use of diathermy for skin incision during inguinal hernioplasty is as safe as the use of scalpel in terms of wound healing ${ }^{4}$. There are others who have reported that the use of diathermy reduces the use of analgesic requirements in 
the postoperative period. But still, some studies have reported that the postoperative analgesic requirement are similar in both the techniques and likewise postoperative complications like seroma, hematoma and purulent collections are comparable amongst the two ${ }^{3}$.

\section{MATERIAL AND METHODS}

This is hospital based comparative study undergoing elective inguinal hernia repair in the department of general surgery at Nepalgunj Medical College, Kohalpur from the period of July 2015 to January 2016. A minimum of 60 cases of elective inguinal hernia repair were taken. The patients were allotted two groups alternately to remove bias. Group A (30 cases): Skin incision with scalpel. Group B (30 cases): Skin incision with electrocautery. Inclusion criteria were (1) All patients diagnosed as inguinal hernia, unilateral or bilateral clinically on admission and posted for hernia repair between the age groups 19-60 years. (2) Patient who agreed to participate in the study and gave a written consent. Exclusion criteria (1) Complicated inguinal hernia like irreducible hernia, obstructed hernia, strangulated hernia, recurrent inguinal hernia. (2) Patients with co-morbidities like immunosuppressed, diabetes mellitus, and on steroids and anticancer therapy.

After taking the detailed history and clinical examination to find out the various modes of presentation and the reasonable risk factors and the informed consent, the patients were allocated alternately into two groups on first come basis after admission. Group A: Here the skin incision was made with scalpel and bleeding was controlled by forceps coagulation using pulse sine wave on power supply of thirty watts. Group B: The skin incision was made with electrocautery needle using pulse sine wave current in "cut" mode and power setting of seventy watts. These 2 groups were compared for the intraoperative incisional time, post operative pain, requirement of analgesia and the quality of wound healing or wound complications and statistical analysis using SPSS (version 20) was done and p value 0.05 was taken as significant.

\section{RESULTS}

1. Incisional time: The incisional time was noted in seconds from the beginning of the skin incision to the dissection of the underlying fascia using either scalpel or cutting diathermy and analyzed using paired t-test.

\begin{tabular}{|c|c|}
\hline Instrument used & Incisional time (seconds) \\
\hline Scalpel & $125.60 \pm 2.89$ \\
\hline Electrocautery & $86.20 \pm 3.49$ \\
\hline
\end{tabular}

Table I: Incisional time (Mean \pm SD)

$t=53.19$ and $D F=29$ which is $>42.56(p<0.002)$ at C.I. $95 \%$ so there is statistically significant difference between the two groups.

\section{Post operative pain:}

The post operative pain was assessed using visual analogue scale at the intervals of 6,12 and $24 \mathrm{hrs}$. In this study results were analyzed using chi-square test as shown in Table III.

\begin{tabular}{|c|c|c|c|}
\hline Time & $\begin{array}{c}\text { Scalpel } \\
\text { incision }\end{array}$ & $\begin{array}{c}\text { Electrocautery } \\
\text { incision }\end{array}$ & $\begin{array}{c}\text { Chi-square } \\
\text { test }\end{array}$ \\
\hline $6 \mathrm{hrs}$ & $6.7 \pm 0.53$ & $6.6 \pm 0.81$ & $\mathrm{P}=0.357$ \\
\hline $12 \mathrm{hrs}$ & $3.73 \pm 0.64$ & $3.83 \pm 0.83$ & $\mathrm{P}=0.741$ \\
\hline $24 \mathrm{hrs}$ & $2.47 \pm 0.50$ & $2.57 \pm 0.85$ & $\mathrm{P}=0.776$ \\
\hline
\end{tabular}

Table II: Pain scores

There is no statistically significant difference between the two groups regarding the quantum of postoperative pain.

\section{Analgesic requirements post operatively:}

The dose of analgesic i.e. injection Diclofenac 75 mg. i.m. was given in both the groups post operatively and the results are shown in table IV. The results were analyzed using Mann Whitney U test.

\begin{tabular}{|c|c|}
\hline Group & $\begin{array}{c}\text { Dose of analgesics } \\
\text { Mean } \pm \text { SD }\end{array}$ \\
\hline Scalpel incision & $1.67 \pm 0.47$ \\
\hline Electrocautery incision & $1.77 \pm 0.67$ \\
\hline
\end{tabular}

Table III: No. of doses of analgesics

\section{$\mathrm{P}=0.610 \quad$ Mann Whitney U test}

There is no statistically significant difference in the dose requirements of analgesics for adequate pain relief among the two groups.

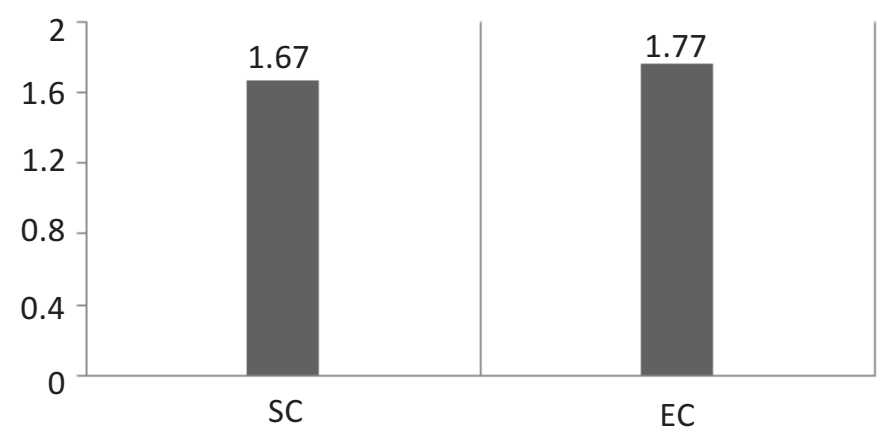

Figure 1: comparison of dose of analgesics 


\section{Local wound complications:}

The overall wound complications viz hematoma, seroma and purulent collections were assessed for 7 days post operatively as shown in table V.

\begin{tabular}{|l|c|c|c|}
\hline Group & Yes & No & Total \\
\hline Scalpel incision & $6(20 \%)$ & 24 & 30 \\
\hline Electrocautery incision & $1(3.33 \%)$ & 29 & 30 \\
\hline
\end{tabular}

Table IV: (a) Hematoma

Chi-square value $=4.138$ which is $<0.05(3.84)$ at $D F=1$, hence there is significant difference between the two groups, the scalpel incision showed more hematoma.

\begin{tabular}{|l|c|c|c|}
\hline Group & Yes & No & Total \\
\hline Scalpel incision & $10(33.3 \%)$ & 20 & 30 \\
\hline Electrocautery incision & $9(30 \%)$ & 21 & 30 \\
\hline
\end{tabular}

Table IV: (b) Seroma

Chi-square value $=2.857$ which is $>0.05(3.84)$ at $D F=1$ and Fischer's exact test $p=0.10$, hence seroma in both the scalpel and electrocautery groups are comparable, the difference is not statistically significant.

\begin{tabular}{|l|c|c|c|}
\hline Group & Yes & No & Total \\
\hline Scalpel incision & $10(33.3 \%)$ & 20 & 30 \\
\hline Electrocautery incision & $9(30 \%)$ & 21 & 30 \\
\hline
\end{tabular}

\section{Table IV: (c) Purulent collection}

Chi-square value $=0.231$ at $D F=1$ and Fisher's exact test $p=0.538$, which is $>0.05$, hence there is no significant difference in purulent collection among the two groups.

\section{DISCUSSION}

Earlier days when explosive anesthetic agents were in use, electrosurgical instruments had limited use because of explosive risks associated with anesthetic agents. After the invention of nonexplosive anesthetic agents like halothane, electrosurgical instruments like diathermy were increasingly used for tissue dissections except for skin incision. This reluctance for use of electrocautery was attributed to the belief that the electrosurgical instruments caused devitalisation of tissue within the wound which consequently lead to wound infection, delayed wound healing and wound scar formation ${ }^{4,7}$.

Surgeons have always been in search of an ideal method of making skin incision which would provide quick and adequate exposure with minimum blood loss. The electrocautery was mainly used for hemostasis and less often for skin incision. ${ }^{4}$ The use of electrosurgery or cold scalpel for making incisions largely depended on surgeon's preference though the conventional diathermy tended to minimize the blood loss and reduce the operating time without compromising the outcome. On the contrary, the surgical scalpels lacked any haemostatic component $^{8}$.

The role of diathermy now is not only limited to general surgical procedures and in fact many clinical trials have compared the usefulness of scalpel and diathermy in making skin incisions in other specialties too ${ }^{9,10}$. The aim of this study was to compare the effect of the cold scalpel and diathermy skin incisions for inguinal hernia repair regarding the incisional time, post operative pain, requirement of analgesic doses and post operative wound complications and only one operation was selected for the study so as to remove the confounding variables in terms of different operations.

The 60 patients of indirect inguinal hernia were allocated alternately into two groups to remove bias, Group A and Group B. The skin incision was made with scalpel in Group $A$ and electrocautery for Group B.

a) The incisional time: In Group $A$ was $125.60 \pm 2.89$ and in Group B, it was $86.20 \pm 3.49$.There was a statistically significant difference in incisional time between the scalpel skin incisions with the diathermy incision $(p<0.002)$. Likewise significant difference for incisional time was seen in a study done by Shamim M (mean $6.25 \pm 0.51$ vs. $\left.9.47 \pm 0.84 \mathrm{~s} / \mathrm{cm}^{2} ; \mathrm{p}<0.001\right)^{20}$. Kearns et al also found that laparotomy incisions using diathermy were significantly quicker than scalpel skin incisions (mean $6.1 \pm 0.4$ vs. $\left.7.5 \pm 0.5 \mathrm{~s} / \mathrm{cm}^{2} ; \mathrm{p}<0.04\right)^{11}$.

b) Postoperative pain scores:- Regarding the postoperative pain assessed by VAS at 6, 12 and $24 \mathrm{hrs}$. postoperatively, the results analyzed with chi-square test resulted in no significant differences between the two groups. The mean pain score at 6 hours for (Group A is $6.7 \pm 0.53$ and for Group B is $6.6 \pm 0.81$; $p=0.357$ ), The mean pain score at $12 \mathrm{hrs}$. for (Group $A$ is $3.73 \pm 0.64$ and for Group $B$ is $3.83 \pm 0.83$; the $p$ value is $(p=0.741)$, The mean pain score at $24 \mathrm{hrs}$. for (Group $A$ is $2.47 \pm 0.50$ and for Group $B$ is $2.57 \pm 0.85$; the $p$ value is $p=0.776$ ). In the study by Hussain results of visual analogue pain scale, the mean pain score for diathermy was $4.35 \pm 2.02$ and for scalpel was $6.75 \pm 2.29$, there was no significant difference at $18 \mathrm{hrs}$ postoperatively $(p>0.05)$ between the two groups ${ }^{12}$. In the study by Shivagouda $P$ et al, the $p$ value at 6 hours was $(p=0.475)$, at 12 hours it was $(p=0.556)$ and at 24 hours it was $(p=0.762)^{4}$.

c) Analgesic requirements: The mean analgesics requirements for scalpel were $1.67 \pm 0.47$ and for electrocautery was 1.77 \pm 0.67 . The parenteral analgesics requirements analyzed using Mann Whitney $U$ test resulted in no significant differences $(p=0.610)$, in the dose requirements of analgesics for adequate pain relief between the two groups. 
In a similar study by Shivagouda $\mathrm{P}$ et $\mathrm{al}^{4}$, the $\mathrm{p}$ value for the doses of analgesics given was (mean $1.6 \pm 0.48$ vs. $1.8 \pm 0.66$ : $\mathrm{p}=0.499)$, analyzed again by Mann Whitney $U$ test. This too shows that the results are comparable with our study.

\section{d) Wound complications:}

In the present study for haematoma, seroma and purulent collection between the two groups, the results were analyzed using Pearson chi-quare test and Fischer's exact test as:

The incidence of hematoma in scalpel group was $20 \%$ but the incidence of hematoma was $3.33 \%$ in electrocautery. The chisquare value resulted 4.138 which is $<0.05$ (3.84) at $D F=1$, hence there was significant difference between the two groups, the scalpel incision showed more hematoma. The seroma collection was $33.3 \%$ in scalpel group and $30 \%$ for electrocautery group. The chi-square value is 2.857 at $D F=1$ and the Fischer's exact test $(p=0.10)$, which is $>0.05$, hence seroma in both the scalpel and electrocautery groups were comparable, the difference is not statistically significant. The purulent collection was seen in $16.7 \%$ of scalpel group and $13.3 \%$ of electrocautery group. The chi-square value is 0.231 at $D F=1$ and Fisher's exact test $(p=0.538)$, which is $>0.05$, hence there was no significant difference in purulent collection among the two groups.

This study of hematoma resulted with significant difference between the two groups, the hematoma being more with scalpel incision but for seroma and purulent collections, the results concluded with no statistically significant differences between the two groups.

In the study by Shivagouda P et $\mathrm{al}^{4}$, Hematoma, $\mathrm{X}_{2}$ with Yates's correction $=2.588$ and $(p=0.108)$, Seroma, $X_{2}$ with Yates's correction $=0.077$ and $(p=0.108)$, Purulent collection, $X_{2}$ with Yates's correction $=0$ and $(p=1)$ : the results were not significant among the two groups.

\section{CONCLUSION}

Skin incision made by cutting diathermy was less time consuming compared to a scalpel skin incision $(p<0.002)$ and there was no significant differences between the two groups regarding the postoperative pain $(p=0.357$ at $6 \mathrm{hrs}, p=0.741$ at12 hrs and $p=0.776$ at $24 \mathrm{hrs}$ ), the requirements of analgesics $(p=0.610)$ and the rate of wound complications like seroma $(p=0.10)$ and purulent collection $(p=0.538)$, though the hematoma was seen more in scalpel skin incision $(p<0.05)$. So the use of diathermy for making skin incision is as safe as use of scalpel in patients undergoing inguinal hernia repair.

\section{REFERENCES}

1. Massarweh NN, Cosgriff N, Slakey DP. Electrosurgery, history, principles and current and future uses. J Am Coll Surg. 2006;202:520-30.

2. Mir MA, Khan M, Iqbal A, Ismail A. Randomized
Comparative Study of Electrosurgical and Conventional Scalpel incisions In General Surgery. 2010;20(25):15-22.

3. Chrysos E, Athanasakis E, Antonakakis S, Xynos E, Xoras O. A prospective study comparing diathermy and scalpel incision in tension free inguinal hernioplasty. Am Surg. 2005;71:326-9.

4. Shivagouda P, Gogeri BV, Godhi AS, Metgud SC. Prospective randomized controlled trial comparing the efficacy of diathermy incision versus scalpel incision over skin in patients undergoing inguinal hernia repair. Rec Res Sci Tech. 2010;2:44-7.

5. Ahmad NZ, Ahmed A. Meta analysis of the effectiveness of surgical scalpel or diathermy in making abdominal skin incisions. Ann Surg. 2011;253(1):8-13.

6. Stolz AJ, Schutzner J, Lischke R, Simonek J, Pafko P. Is a scalpel required to perform a thoracotomy? Rozhl Chir. 2004;83(4):185-8.

7. Shamim M. Diathermy vs. scalpel incisions in general surgery, double-blind, randomized, clinical trial. World J Surg. 2009;33:1594-9.

8. Assiotis A, Christofi T, Raptis DA, A. Engledow, C. Imber, A Huang. Diathermy training and usage trends among surgical trainees-will we get our fingers Burnt? Surgeon. 2009;7(3):132-6.

9. Groot G, Chappell W. Electrocautery used to create incisions does not increase wound infection rates. Am J Surg. 1994;167(6):601-3.

10. Sheikh B. Safety and efficacy of electrocautery scalpel utilization for skin opening in neurosurgery. BJS. 2004;18:268-72.

11. Kearns SR, Connolly EM, Mc Nally S, McNamara DA, Deasy J. Randomized clinical trial of diathermy versus scalpel incision in elective midline laparotomy. BJS. 2001;88:41-4.

12. Hussain SA and Hussain S. Incision with knife or diathermy and postoperative pain. BJS. 1988;75:1179-80. 